Check for updates

Cite this: RSC Adv., 2017, 7, 50113

Received 24th July 2017

Accepted 23rd October 2017

DOI: 10.1039/c7ra08152a

rsc.li/rsc-advances

\section{The effect of size and concentration of nanoparticles on the glass transition temperature of polymer nanocomposites $\dagger$}

\author{
Olga A. Serenko, ${ }^{\text {*a } V y a c h e s l a v ~ I . ~ R o l d u g h i n, ~}{ }^{\mathrm{b}}$ Andrey A. Askadskii, ${ }^{a}$ Elena S. Serkova, ${ }^{a}$ \\ Pavel V. Strashnov (ID a and Zinaida B. Shifrina (D)
}

\begin{abstract}
Numerous studies have reported a possibility of alteration of the polymer glass transition temperature $\left(T_{\mathrm{g}}\right)$ by the introduction of nanoscale particles. Here we use model nanocomposites based on polystyrene and polyphenylene dendrimers to show both theoretically and experimentally that inclusion of rigid nanoparticles of 2.3-5 nm size into the polymer leads to a negligible $T_{\mathrm{g}}$ increase, not exceeding the experimental measurement error. Furthermore, we establish a strategy for preparation of the polymer nanocomposites with $T_{\mathrm{g}}$ modified significantly from a practical point of view. We find that to form a uniform distribution in the polymer matrix the size of thermodynamically compatible nanoparticles should not exceed $2.3 \mathrm{~nm}$. An increase of the particle diameter by $2 \mathrm{~nm}$ inevitably leads to the formation of filler aggregates.
\end{abstract}

The possible influence of nanoparticle size and concentration on the glass transition temperature of polymeric nanocomposites $\left(T_{\mathrm{g}}\right)$ is actively investigated and discussed in the scientific literature. To date, several theoretical approaches have been developed that determine the contribution of nanoparticles to segmental dynamics of macromolecules. ${ }^{1-7}$ In most cases, these approaches are based on concepts that can be described in a simplified way as follows:

- The polymer wets the surface of the nanoparticle, which suggests an increase in $T_{\mathrm{g}}$ with an increase in the content of the nanosized filler;

- The polymer does not wet the surface of the filler and, therefore, $T_{\mathrm{g}}$ decreases with increasing content of nanoparticles;

- Immobilization of macromolecules on the surface of the filler takes place, which leads to an increase in $T_{\mathrm{g}}$.

Experimental studies, where increase, permanence, or decrease of the glass transition temperature of polymers with $\mathrm{SiO}_{2}$ nanoparticles, were discussed in a critical review. ${ }^{8}$ It was noted that in the absence of clear understanding of the role of nanoparticles to explain the experimental results of a particular $T_{\mathrm{g}}$ study, authors pick one of the above options, which is the most acceptable for their system. This situation does not bring us closer to the understanding of the role of nanosized filler in the polymer and, ultimately, to determining the advantages of using nanoparticles in the composition.

${ }^{a}$ Russian Academy of Sciences, A. N. Nesmeyanov Institute of Organoelement Compounds, Moscow, 119991, Russia. E-mail: strashnov@ineos.ac.ru

${ }^{b}$ Russian Academy of Sciences, A. N. Frumkin Institute of Physical Chemistry and Electrochemistry, Moscow, 119071, Russia

$\dagger$ Electronic supplementary information (ESI) available. See DOI: 10.1039/c7ra08152a
The current state in the field of polymer nanocomposites is complicated in many respects by the aggregation of nanoparticles in the polymer matrix ${ }^{9}$ and the necessity to develop methods for preventing the formation of dispersed phase aggregates as well as preserving their initial (or individual) dimensions and uniform distribution of nanoparticles in the polymer. One of the solutions to the problem is to modify the surface of the nanosized filler by grafting functional groups that should ensure compatibility with the polymer matrix or form chemical bonds with the functional groups of the polymer. ${ }^{\mathbf{1 0 - 1 2}}$

However, the surface layer of the nanoparticle can act as a plasticizer for the matrix. ${ }^{\mathbf{1 3 - 1 5}}$ This effect disguises the effect of the nanoparticle itself on the composition properties. Thus, based on the results of thermodynamic analysis of polymer/ hybrid nanoparticles systems with a core-shell structure, it was shown that the increase or decrease in $T_{\mathrm{g}}$ depends on the competition of two main factors: ${ }^{16}$

- An increase in the number of degrees of freedom and the system entropy because of the presence of an organic layer on the surfaces of nanoparticles;

- A decrease of the system entropy and the number of configuration states of the macromolecules in the presence of nanoinclusions.

The first of them leads to a drop in the glass transition temperature of the composition, while the second one leads to its rise since the contribution of the plasticizing effect of the nanoparticle surface layer to the nanocomposite properties decreases with an increase of its size.

Another approach to the preparation of nanocomposites is based on the use of a filler with a particle radius comparable to or smaller than the gyration radius of the macromolecule $R_{\mathrm{g}}{ }^{17,18}$ 
in another version with a particle diameter comparable or smaller than the monomeric unit of the polymer chain. ${ }^{7,19,20}$ For a wide range of polymers, the particles with a size of 2 to $5 \mathrm{~nm}$ meet these criteria. It is assumed that in this case, it is possible to obtain composites without filler aggregation avoiding a surface modification. According to M. E. Mackay et al., the introduction of particles with similar dimensions into the polymer can change the radius of gyration of the macromolecule as well as its conformational mobility, relaxation, and rheological characteristics, e.g., $T_{\mathrm{g}}$. The polymer glass transition temperature depends on the segmental mobility of the macromolecular chain. ${ }^{21,22}$ Numerous studies $^{\mathbf{2 3 , 2 4}}$ discuss these dependencies and either confirm or refute the expected changes.

To study the effects of such small sized particles $(2-5 \mathrm{~nm})$ on the nanocomposite properties, it is convenient to use model nanoobjects, for example, dendrimers - regularly branched macromolecular particles. In this case, the monodispersity and similarity of the nanoparticle shape are predetermined by their structure formed as a result of controlled synthesis. ${ }^{25-27}$ However, to the best of our knowledge, the studies on polymer/ dendrimers blends are not numerous. ${ }^{27-32} \mathrm{~S}$. K. Emran studied 12-tert-butyl ester dendrimer/poly(methyl methacrylate) blends. ${ }^{29}$ It was found that dendrimers of the 2 nd generation are plasticizers of poly(methyl methacrylate), and their introduction into the polymer leads to a decrease in the glass transition temperature of the blends. The plasticizing effect of dendrimers was also noted by B. M. Tande et al. ${ }^{30}$ In this case, blends of polyvinyl chloride and poly(propylene imine) dendrimers of the 4 th and 5 th generations were studied. The study of blends of polystyrene (PS) and carbosilane dendrimers with [dimethyl(2-phenylethyl)silyl]propyl groups in the external layer demonstrated that with an increase in the content of dendrimers of the first, second, and sixth generation, the $T_{\mathrm{g}}$ of the systems have decreased, unchanged and increased, correspondingly. ${ }^{31}$

It should be noted that the used dendrimers ${ }^{27-31}$ are "soft" (flexible-chain) organic nanoparticles characterized by an intrinsic glass transition temperature that is lower than the glass transition temperature of the matrix. When rigid aryl ether dendrimers of the 1st and 2nd generations, whose melting points were 190 and $152{ }^{\circ} \mathrm{C}$, respectively, were introduced into polyethylene terephthalate, ${ }^{32}$ no significant effect on the $T_{\mathrm{g}}$ was observed. Thus, at a concentration of 1 st generation dendrimers of 5 and $10 \mathrm{wt} \%, T_{\mathrm{g}}$ decreased by 1 and 2 degrees, respectively; while a 3rd generation dendrimer was used, $T_{\mathrm{g}}$ remained unchanged.

In this work, rigid polyphenylene dendrimers of the 1st and 3rd generations were used as nanoparticles. The absence of functional groups on the surface of these particles allows, first, to exclude from consideration the possible plasticizing effect of the outer functional layer and, second, to determine the effect of the concentration and size of small rigid particles on the glass transition temperature of the matrix. Based on the thermodynamic approach to the evaluation of glass transition temperature of composites with rigid model nanoparticles, we theoretically assessed and experimentally proved that the high hopes associated with small size nanoparticles were not justified. Small rigid nanoparticles do not show a significant effect on the glass transition temperature of a nanocomposite, that can be reliably determined by experimental methods and whose variation would have an impact on the temperature range of the material usage.

\section{Results and discussion}

\section{Determination of compatibility of the composition components}

It is known that the components of the mixture are thermodynamically compatible in case of the following inequality: $:^{33,34}$

$$
\frac{\delta_{\mathrm{p}}^{2}}{\delta_{\mathrm{s}}^{2}}\left(\frac{M}{M_{0}}\right)^{1 / 6}<\left[2 \rho \Phi\left(\Phi-\sqrt{\Phi^{2}+\frac{\gamma_{\mathrm{p}}}{\gamma_{\mathrm{s}}}-2 \Phi\left(\frac{\gamma_{\mathrm{p}}}{\gamma_{\mathrm{s}}}\right)^{1 / 2}}\right)\right]
$$

where $\Phi=\frac{4\left(V_{\mathrm{s}} V_{\mathrm{p}}\right)^{1 / 3}}{\left(V_{\mathrm{s}}^{1 / 3}+V_{\mathrm{p}}^{1 / 3}\right)^{2}}, M_{0}=200000-$ molecular weight of the polymer with polymerization degree $N_{0}=1920$ for PS; $M-$ molecular weight of the polymer; $\delta_{\mathrm{p}}, V_{\mathrm{p}}, \gamma_{\mathrm{p}}$, and $\delta_{\mathrm{s}}, V_{\mathrm{s}}, \gamma_{\mathrm{s}}-$ are solubility parameter, molar volume, surface tension of the polymer and solvent, respectively, $\rho$ is the universal constant equaled to $0.687 .^{33,34}$

The required for assessment of the components compatibility values of the solubility parameters, surface tension and molar volumes of PS, F1, and F3 are given in Table 1. If the following abbreviations are accepted:

$$
\begin{aligned}
& \mathrm{A}=\frac{\delta_{\mathrm{p}}{ }^{2}}{\delta_{\mathrm{s}}{ }^{2}}\left(\frac{M}{M_{0}}\right)^{1 / 6} \\
& \mathrm{~B}=\left[2 \rho \Phi\left(\Phi-\sqrt{\Phi^{2}+\frac{\gamma_{\mathrm{p}}}{\gamma_{\mathrm{s}}}-2 \Phi\left(\frac{\gamma_{\mathrm{p}}}{\gamma_{\mathrm{s}}}\right)^{1 / 2}}\right)\right]
\end{aligned}
$$

then inequality (2) can be written as $A<B$. The values of the required parameters for studied systems at $298 \mathrm{~K}$ are shown in Table 2. As it follows from the presented data, $M_{\mathrm{n}}$ of PS corresponding to the compatibility with the 1st generation polyphenylene dendrimer is $150 \mathrm{kDa} . M_{\mathrm{n}}$ of the matrix polymer is 86 $\mathrm{kDa}$. According to data obtained, the components of the PS/F1 system have high compatibility.

For the mixture of PS with F3, compatibility of the matrix polymer with the terminal groups of the dendrimer was estimated. The fragment of the structure of the dendrimer terminal groups is given below:

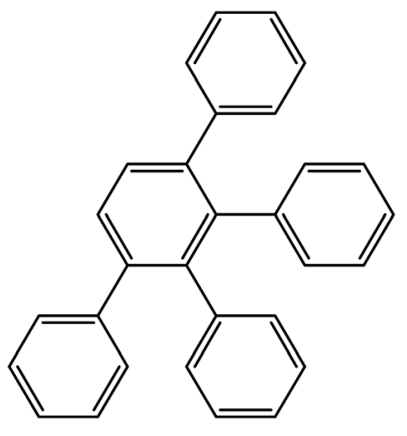


Table 1 Parameters required for the assessment of thermodynamic compatibility between PS and polyphenylene dendrimers

\begin{tabular}{|c|c|c|c|}
\hline Components & $\begin{array}{l}\text { Molar volume, } \\
V,\left(\mathrm{~cm}^{3} \mathrm{~mol}^{-1}\right)\end{array}$ & $\begin{array}{l}\text { Solubility } \\
\text { parameter, } \\
\delta,\left(\mathrm{J} \mathrm{cm}^{-3}\right)^{0.5}\end{array}$ & $\begin{array}{l}\text { Surface tension, } \\
\gamma,\left(\mathrm{mN} \mathrm{m}^{-1}\right)\end{array}$ \\
\hline PS & 97.1 & 18.7 & 40.4 \\
\hline $\mathrm{F} 1$ & 1240 & 19.6 & 70.7 \\
\hline $\begin{array}{l}\text { Terminal groups } \\
\text { of the F3 dendrimer }\end{array}$ & 1160 & 19.6 & 69.2 \\
\hline
\end{tabular}

Table 2 Values of $A$ and $B$ parameters in the inequality (2) for the system "PS/polyphenylene dendrimers"

\begin{tabular}{|c|c|c|c|}
\hline$M_{\mathrm{n}} \mathrm{PS}, \mathrm{kDa}$ & $A$ & $B$ & Compatibility \\
\hline \multicolumn{4}{|l|}{ PS/F1 } \\
\hline 140 & 0.858 & 0.871 & + \\
\hline 150 & 0.868 & 0.871 & + \\
\hline 160 & 0.877 & 0.871 & - \\
\hline \multicolumn{4}{|c|}{ PS/terminal groups of the F3 } \\
\hline 300 & 0.984 & 0.998 & + \\
\hline 400 & 1.032 & 0.998 & - \\
\hline
\end{tabular}

The values of the required parameters are given in Table 1, and the results of the calculation are presented in Table 2 . According to the data obtained, the surface groups of the thirdgeneration dendrimer are well compatible with PS. Considering the fact that the size of F3 meets the requirements for avoiding its aggregation in polymer matrix, namely, the radius of these nanoparticles $(2.5 \mathrm{~nm})$ is less than $R_{\mathrm{g}}$ of the polymer, ${ }^{17}$ which is equal to $12.5 \mathrm{~nm},{ }^{35}$ a uniform distribution of F3 dendrimers in PS can be expected (dendrimers do not form aggregates).

\section{Morphology of PS/dendrimer compositions}

The obtained PS/F1 films in the studied range of nanoparticle concentrations are transparent, indicating a good compatibility of the dendrimer with the matrix polymer, which agrees with the results of the evaluation of thermodynamic compatibility. The absence of dendrimer aggregates in PS is also confirmed by the results of electron microscopy. Fig. 1(a and b) shows TEM images of a sample containing $3 \mathrm{wt} \%$ of $\mathrm{F} 1$. The film is homogeneous.

Unlike PS/F1 blends, PS/F3 films are transparent if the amount of the dendrimers does not exceed $1 \mathrm{wt} \%$. The film is characterized with a slight opalescence at an F3 concentration of $2 \mathrm{wt} \%$, while at $3 \mathrm{wt} \%$ of $\mathrm{F} 3$ the compositions become turbid. Fig. 1(c and d) shows TEM images of a PS-based sample containing $3 \mathrm{wt} \%$ of F3. Aggregates up to $650 \mathrm{~nm}$ in size are observed in the polymer. They can also be detected with the use of an optical microscope (Fig. 1e). The result obtained is somewhat unexpected. As it was mentioned above, the surface groups of an F3 nanoparticle are compatible with PS, and the F3 radius is less than $R_{\mathrm{g}}$ of the matrix polymer. It is evident that the formation of aggregates and, consequently, the mixture microphase separation is depended on the nanoparticle size. A similar behavior was observed in work, ${ }^{36}$ where particles with a radius of $2 \mathrm{~nm}$ containing the surface groups which are thermodynamically compatible with the polymer (PS), formed aggregates in its bulk. The similarity of the results indicates the dependence of compatibility of nanoparticles with the matrix polymer on their size. Consequently, the fulfillment of the requirements ${ }^{17,18}$ which assume the absence of aggregation if the radius of nanoparticles is smaller than the gyration radius of the macromolecule, is not a guarantee of preventing aggregation of a nanosized filler.

\section{Glass transition temperature of PS/dendrimer blends}

Polyphenylene dendrimers are rigid-chain polymers, and their glass transition temperature exceeds the decomposition temperature. Fig. 2 shows the dendrimer concentration dependence of the glass transition temperature of the composites. It is worth noting that according to the results of thermogravimetric analysis the mixture does not contain residual solvent. The results presented in the figure indicate the similarity of $T_{\mathrm{g}}$ of the studied systems with that of PS as differences do not exceed 0.5-0.6 ${ }^{\circ} \mathrm{C}$. Consequently, rigid, structurally uniform nanoparticles (not containing a surface plasticizing layer) with a size of 2.3 and $5.0 \mathrm{~nm}$ do not have a significant effect on the glass transition temperature of the matrix polymer at the concentration of nanoparticles lesser than 3 vol\%. Y. Tai et al. ${ }^{\mathbf{1 1 , 1 2}}$ and some authors as analyzed in the review $^{8}$ have obtained similar results.

\section{Thermodynamic analysis of the glass transition temperature of amorphous polymer/nanoparticle composites}

A thermodynamic approach to the analysis of concentrationdependent changes in $T_{\mathrm{g}}$ of nanocomposites based on amorphous polymer and nanoparticles with a core-shell structure, which includes the internal configuration entropy of the hybrid nano-inclusions was developed earlier. ${ }^{16}$

To describe the concentration-dependent change in the glass transition temperature of a polymer filled with polyphenylene dendrimers, we use the approaches proposed earlier ${ }^{16}$ assuming the structural uniformity and monodispersity of the particles. In this case, the equation describing the glass transition temperature of the composite takes the form:

$$
\begin{aligned}
\ln \left(\frac{T_{\mathrm{g}}}{T_{\mathrm{g} 0}}\right)= & \frac{R}{M_{\mathrm{p}} \Delta C_{\mathrm{p}}(1-\phi)}\left\{\frac{\phi}{N_{\mathrm{p}}} \ln \phi+\frac{1-\phi}{N} \ln (1-\phi)\right. \\
& +\phi \ln \left(\frac{Z-1}{e}\right) \tanh ^{2}\left(R_{\mathrm{p}} / R_{\mathrm{K}}\right)-\frac{\phi}{N} \ln 2 \\
& +\frac{4 \phi-3 \phi^{2}}{1-\phi} \frac{\phi}{N_{\mathrm{p}}}-\frac{\phi}{N_{p}} \ln \left(8 \pi^{2}\right)+3 \frac{\phi}{N_{\mathrm{p}}} \ln \left(R_{\mathrm{p}} / R_{0}\right) \\
& \left.+\frac{4}{3} \frac{\phi}{N_{\mathrm{p}}} \pi\left(\frac{{R_{\mathrm{p}}}^{3}-R_{\delta}{ }^{3}}{R_{0}{ }^{3}}\right) \ln \nu\right\} .
\end{aligned}
$$

Here $T_{\mathrm{g} 0}$ is glass transition temperature of the matrix polymer, $N_{\mathrm{p}}=\frac{4 \pi R_{\mathrm{p}}{ }^{3}}{3 R_{0}{ }^{3}}, R$ is the gas constant; $M_{\mathrm{p}}$ is the molar mass of the 

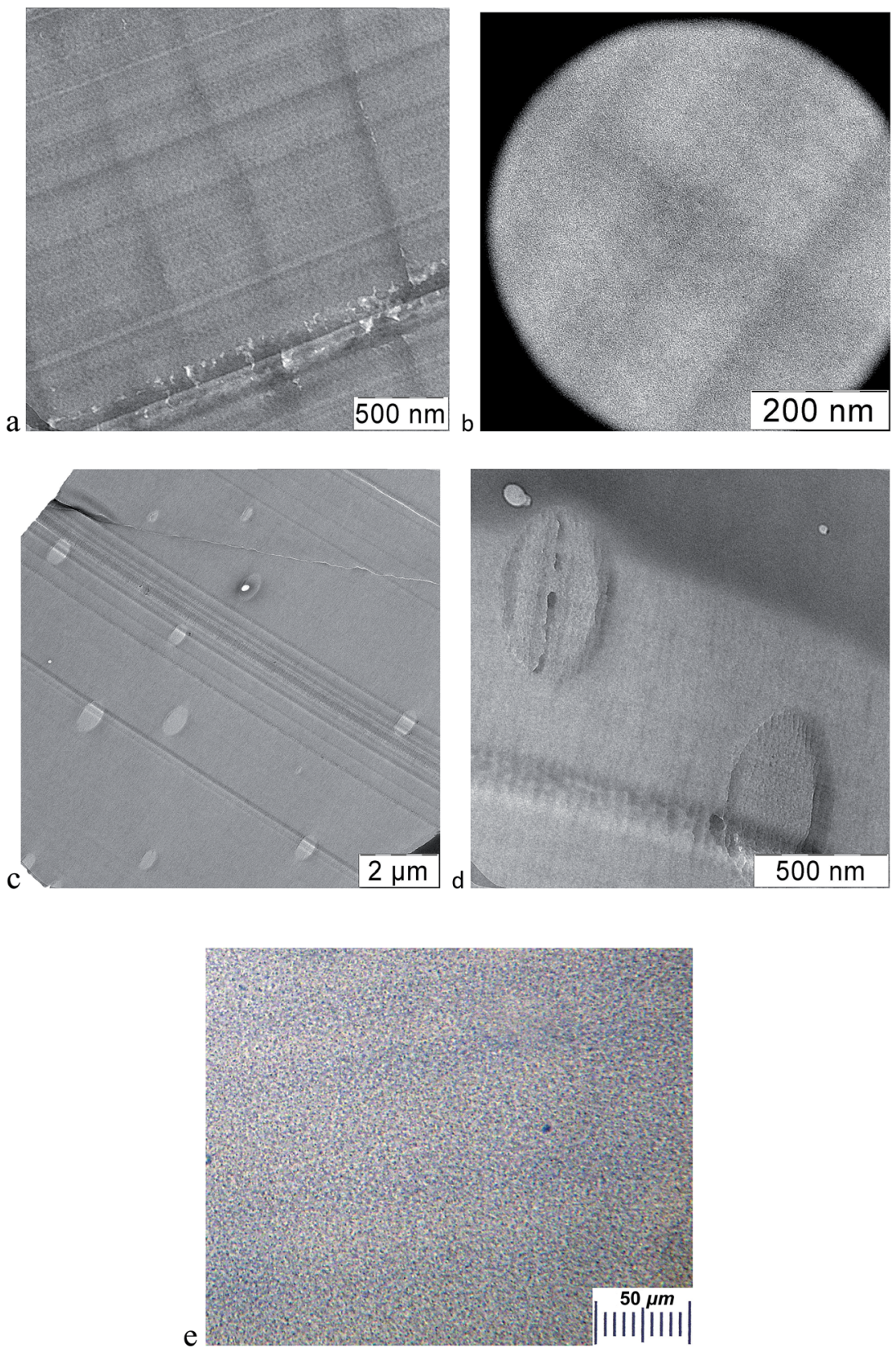

Fig. 1 TEM images $(a-d)$ and an optical photograph (e) of PS-based samples containing 3 wt\% dendrimers of the first F1 (a, b) and the third F3 generation (c-e). TEM images at different magnifications were taken. TEM images show the homogeneous distribution of F1 in PS. F3 dendrimers form aggregates in the polymer. Black dots in optical microscope photograph (e) correspond to the dendrimer aggregates.

monomer unit; $\Delta C_{\mathrm{p}}, \mathrm{J}(\mathrm{g} \mathrm{K})^{-1}$, is change in heat capacity of the polymer upon vitrification; $R_{\mathrm{K}}$ is the Kuhn segment size of polymer matrix; $R_{0}$ is the unit cell size, and $R_{\mathrm{p}}$ is the particle radius including the modified surface layer; $N$ - degree of polymerization; $N_{\mathrm{p}}$ is number of unit cells, occupied by particles; $R_{\delta}=R_{\mathrm{p}}-\delta ; \delta$ - thickness of the surface layer, which elements might have different orientation in the dendrimer, $Z$ is the coordination number of macromolecules; $\varphi$ - volumetric fraction of particles, $\nu$ - number of degrees of freedom associated with the different orientation of the elements of the surface layer.
The summands in the braces of eqn (3) have the following physical meaning. The first four are related to the entropy of mixing, considering the different configurations of polymer molecules in the presence of particles. The multiplier $\tanh \left(R_{\mathrm{p}} /\right.$ $R_{\mathrm{K}}$ ) excludes the influence of particles on the configuration of the polymer molecule when their size is smaller than the length of the Kuhn segment. The fifth summand considers the steric interaction of dendrimers with each other. Finally, the last three summands are related to the contribution of different orientations of the particles to the entropy as a whole and segments in the $\delta$ thick surface layer. 


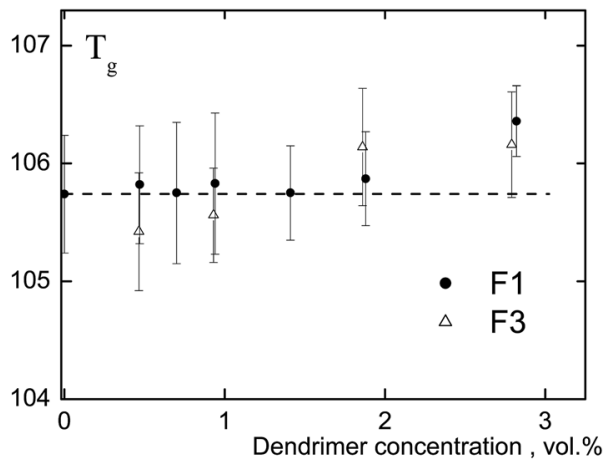

Fig. 2 The dependence of $T_{g}$ of the PS-composite on polyphenylene dendrimer concentration. F1 is the 1st and F3 is 3rd dendrimer generation. The particle size: $2.3 \mathrm{~nm}$ (F1) and $5.0 \mathrm{~nm}$ (F3). The dashed line indicates the glass transition temperature of PS. The difference between $T_{g}$ of composites and pure PS is $0.5-0.6{ }^{\circ} \mathrm{C}$ and can be regarded as an experimental error

Upon the calculation of the glass transition temperature of $\mathrm{PS} /$ dendrimer composites, the value of parameter $Z$, which characterizes the coordination number of segments of the PS macromolecule, was taken equal to $9 .^{16,31}$ Fig. 3 shows the obtained dependences of the $T_{\mathrm{g}}$ changes on the content of rigid dendrimers. The thickness of the surface layer $\delta$, whose values were 0 and $0.42 \mathrm{~nm}$, was used as the variation parameter. The first option ( $\delta=0 \mathrm{~nm})$ assumes an absolute rigidity of the polyphenylene dendrimers (Fig. 3, curves 1 and 2), i.e., their units have a strictly fixed conformation. It should be noted that for a zero value of the surface layer, $R_{\delta}=R_{\mathrm{p}}$, the last summand in eqn (3), which includes parameter $\nu$, also becomes zero. It can be seen from the figure, that for the PS/F1 system this approximation leads to an increase of the glass transition temperature, however, the values of the positive $T_{\mathrm{g}}$ shift in the investigated concentration range of $\mathrm{F} 1$ do not exceed $1{ }^{\circ} \mathrm{C}$ and correspond to

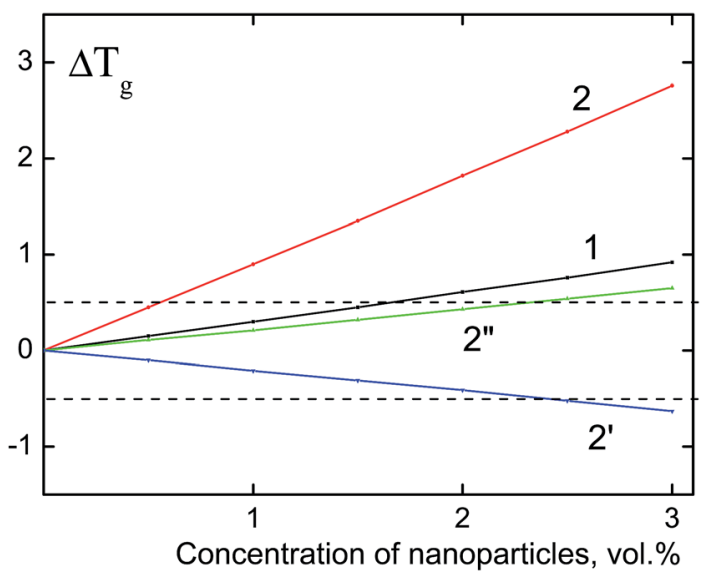

Fig. 3 The theoretical dependences of the composite glass transition temperature $\left(\Delta T_{\mathrm{g}}\right)$ on the concentration of nanoparticles. Particle size: $2.3 \mathrm{~nm}(1)$ and $5.0 \mathrm{~nm}\left(2,2^{\prime}, 2^{\prime \prime}\right)$. The calculation is performed using eqn (3) with the following parameter values: $\delta=0, Z=9(1,2) ; \delta=0,42, \nu=$ $7, Z=9\left(2^{\prime}\right) ; \delta=0,42, \nu=3, Z=9\left(2^{\prime \prime}\right)$. The dashed lines indicate the experimental range of the glass transition temperature of nanocomposites $\left( \pm 0.5^{\circ} \mathrm{C}\right)$. the experimental data. For dendrimers of the third generation $\mathrm{F} 3$, the shift in the glass transition temperature $\left(\Delta T_{\mathrm{g}}\right)$ reaches $2.8{ }^{\circ} \mathrm{C}$ and slightly exceeds the mean error of the experimental values. The obtained result indicates the absence of absolute rigidity in dendrimers of the third generation, and for the PS/F3 system, the value of $\delta$ is probably different from zero.

In the second version of calculation, the thickness of the surface layer is equal to the size of the phenyl ring of the terminal group of the dendrimer $(\delta=0.42 \mathrm{~nm})$ assuming a "defrosting" of the surface layer of nanoparticles to the "depth". "Defrosting" implies the appearance of different degrees of freedom of the segments, in particular, their rotations. Similar to the mixture "PS/flexible-chain carbosilane dendrimer"16,31 the parameter $\nu$ was assumed to be equal 7 upon the calculation of the glass transition temperature. Fig. 3 (curve $2^{\prime}$ ) shows the decrease of the glass transition temperature of PS/ F3 with an increase of nanoparticle content, however, the value of $\Delta T_{\mathrm{g}}$ does not exceed $0.6{ }^{\circ} \mathrm{C}$ in the analyzed concentration range. Since polyphenylene dendrimers are rigid-chain nanoparticles, $T_{\mathrm{g}}$ was calculated at $\nu=3$ (Fig. 3 , curve $2^{\prime \prime}$ ). In this case, a better agreement with the experimental data is achieved, and the glass transition temperature of the PS/F3 system increases with the increase of the dendrimer concentration, but the value of the positive shift of $T_{\mathrm{g}}$ does not exceed $0.65{ }^{\circ} \mathrm{C}$.

Taking into account the performed thermodynamic analysis of the changes in the glass transition temperature of the nanocomposites, it can be concluded that incorporation of rigid nanosized particles with a size of $2.3-5.0 \mathrm{~nm}$ into the polymer should result in increase of $T_{\mathrm{g}}$ of the system, however the value of this increase at a concentration of nanoparticles lesser than 3 vol\% does not exceed the experimental error. In practice, the introduction of nanoparticles does not affect significantly on $T_{\mathrm{g}}$ of the material.

Thus, to obtain a material with a uniform distribution of nanoparticles at their content of $3 \mathrm{vol} \%$, the latter should be thermodynamically compatible with the matrix polymer and have a size of $2.3 \mathrm{~nm}$. An increase of the particle size inevitably leads to aggregation of the filler, despite its compatibility with the matrix. It has been theoretically and experimentally shown that nanoparticles of this size are not capable significantly change the $T_{\mathrm{g}}$ of the material. An increase in the concentration of nanoparticles (more than 3-5 vol\%) with a size of $2-3 \mathrm{~nm}$ promotes the formation of aggregates ${ }^{\mathbf{1 6 , 3 6 - 3 9}}$ and, as a consequence, prevents the expected effect of the nanosized filler on the glass transition temperature.

The use of particles bigger than 2-2.3 nm leads to their unavoidable aggregation. ${ }^{37,40}$ Thermodynamic analysis of these systems, which does not take into account the existence of aggregates in the volume of the polymer, predicts an increase in $T_{\mathrm{g}}$ of the composites. However, the positive shift of this characteristic of the sample does not exceed the usual statistical (or arithmetic mean) spread of the obtained values of $T_{\mathrm{g}}$. Consequently, in this case, the expected effects of nanosized particles on this important characteristic of polymer nanocomposites are not justified either. We particularly emphasize that this conclusion refers to nanocomposites in which there are no interactions between the nanoparticles and the polymer matrix. 


\section{Conclusions}

The thermodynamic analysis of systems with nanosized particles shows that the high hopes associated with small size nanoparticles were not justified. The introduction of rigid nanoparticles of $2.3-5 \mathrm{~nm}$ size into the polymer leads to a negligible increase in the glass transition temperature of the system, but this increase does not exceed the experimental measurement error at the nanoparticle concentration less or equal to $3 \mathrm{vol} \%$. It is necessary to change the general strategy for polymer nanocomposite preparation in which nanoparticles would contribute to a significant increase in their glass transition temperature. One of the factors of "control" over properties of the future material with nano-sized particles can be the directed formation of the nanoparticle/polymer surface layer, composed of the polymer near the nanoparticle and the surface layer of the particle itself. ${ }^{8}$ Possibly, finding of the conditions for its formation, understanding the function of this layer, its contribution to the properties of the future material, will disclose the "mystery" of nanoparticles in the polymer.

\section{Materials and methods}

PS $\left(\mathrm{PSM}-115, M_{\mathrm{w}}=1.9 \times 10^{5}, M_{\mathrm{w}} / M_{\mathrm{n}}=2.22\right.$, density $1.045 \mathrm{~g} \mathrm{~cm}^{-3}$ ) was used. Polyphenylene dendrimers of the $1 \mathrm{st}$ and 3rd generation (from now on referred to as F1 and F3, respectively) were used as nanosized fillers. Their structural formulae are given below:

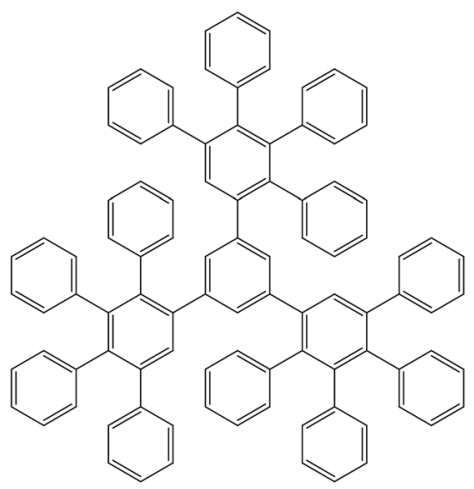

F1
To obtain PS/dendrimer compositions we prepared solutions of PS and dendrimers (F1 or F3) in benzene. Then, a solution of the dendrimer in $5 \mathrm{ml}$ of benzene was added dropwise to a solution of polymer ( $0.785 \mathrm{~g}$ of PS in $10 \mathrm{ml}$ of benzene) while stirring with a magnetic stirrer. After the total amount of dendrimer was introduced, the resulting solution was aged with stirring for 40 minutes, after which it was precipitated in $400 \mathrm{ml}$ of ethyl alcohol. The white product was filtered on a Schott glass filter and dried in a vacuum oven at $110{ }^{\circ} \mathrm{C}$ until constant weight. The average drying time was 24 hours. The presence of residual solvent in the mixture was monitored by thermogravimetry analysis. The concentration of dendrimers in the PS was varied from 0 to $3 \mathrm{wt} \%$. The weight concentrations and their corresponding volume concentrations of dendrimers in PS are presented in the ESI. $\dagger$

The resulting blends were used for producing $200 \mu \mathrm{m}$ thick films by hot pressure molding at $180{ }^{\circ} \mathrm{C}$ and $10 \mathrm{MPa}$. The samples were maintained under pressure for $5 \mathrm{~min}$ at $180{ }^{\circ} \mathrm{C}$ and for an additional 5 min when cooling. The PS/F1 films were colorless and transparent, and in the case of PS/F3, they were of a light-yellow color. When analyzing the properties of the compositions, a PS film obtained under similar conditions served as a reference sample.

The blends were studied by thermogravimetric analysis with the help of "Derivatograph-C" instrument (MOM, Hungary) at a heating rate of $10^{\circ} \mathrm{min}^{-1}$ in argon on $\approx 20 \mathrm{mg}$ samples.

The morphology of the samples was examined by transmission electron microscopy using the LEO912 AB Omega microscope (Karl Zeiss, Germany). Preliminarily, thin slices not

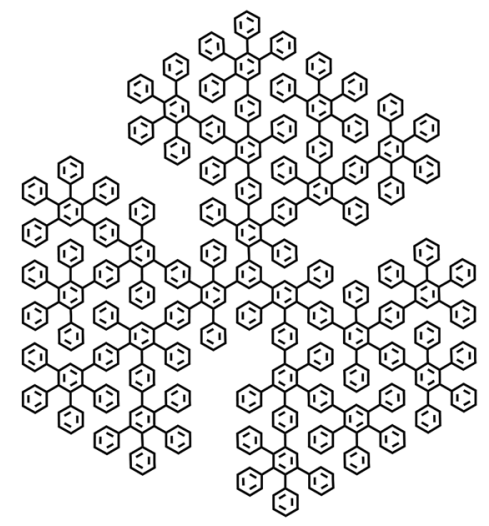

F3
Synthesis of dendrimers was carried out according to a procedure published elsewhere. ${ }^{\mathbf{4 1}}$ The particle size, assessed using molecular mechanics simulations, was shown to be $2.3 \mathrm{~nm}$ for $\mathrm{F} 1$ and $5.0 \mathrm{~nm}$ for F3. ${ }^{42}$

The density of the dendrimers was determined by gel pycnometry using an automatic helium pycnometer AccuPyc 1340 (Micromeritics Instrument Corp., USA). The values obtained are $1.114 \pm 0.002$ and $1.123 \pm 0.003 \mathrm{~g} \mathrm{~cm}^{-3}$ for $\mathrm{F} 1$ and $\mathrm{F} 3$, respectively. more than $100 \mathrm{~nm}$ thick were obtained using a ultramicrotome Reichert-Jung with a diamond knife.

Also, an optical microscope Eclipse 55i (Nikon, Japan) equipped with a digital imaging record system was used.

The glass transition temperature of the compositions was determined by differential scanning calorimetry on a Mettler Toledo $822 \mathrm{E}$ thermal analyzer at a heating rate of $10^{\circ} \mathrm{C} \mathrm{min}^{-1}$. $T_{\mathrm{g}}$ of the sample was assumed to be the temperature corresponding to the inflection point in the devitrification stage of the material during re-scanning the temperature. 
The thermodynamic compatibility of PS with dendrimers was calculated using the method described elsewhere ${ }^{33,34}$ with the CASCADE software. The known equations were used to evaluate the following characteristics:

$\delta$ solubility parameter $\left(\mathrm{J} \mathrm{cm}^{-3}\right)^{0.5}$ :

$$
\delta^{2}=\frac{\sum_{i} \Delta E_{i}^{*}}{N_{\mathrm{A}}\left(\sum_{i} \Delta V_{i}\right)}
$$

$\gamma_{\mathrm{s}}$ "solvent" and $\gamma_{\mathrm{p}}$ polymer surface tension $\left(\mathrm{mN} \mathrm{m}^{-1}\right)$ :

$$
\begin{gathered}
\gamma_{\mathrm{s}}=A_{\mathrm{j}} \frac{\sum_{i} \Delta E_{i}^{*}}{\left(\sum_{i} \Delta V_{i}\right)^{2 / 3}} \\
\gamma_{\mathrm{p}}=\mathrm{C}_{\mathrm{j}} \frac{\sum_{i} \Delta E_{i}^{*}}{\left(\sum_{i} \Delta V_{i}\right)^{2 / 3} m^{1 / 3}}
\end{gathered}
$$

$V$ is the molar volume $\left(\mathrm{cm}^{3} \mathrm{~mol}^{-1}\right)$ :

$$
V=\frac{N_{\mathrm{A}} \sum_{i} \Delta V_{i}}{k_{\mathrm{cp}}}
$$

where $\Delta E_{i}^{*}$ is contribution of each atom and type of intermolecular interaction to the cohesion energy of the low-molecular weight compound or polymer; $\sum_{i} \Delta V_{i}$ is van der Waals volume of the solvent molecule or a repeating unit of the polymer; $N_{\mathrm{A}}$ is Avogadro's number; $A_{\mathrm{j}}$ is a factor associated with coefficients of the molecular packing of liquid molecules in bulk and on the surface; $C_{\mathrm{j}}$ is the parameter associated with the molecular packing coefficients of polymers and is dependent on the polymer type; and $m$ is the number of atoms in the polymer repeating unit, $k_{\mathrm{cp}}$ is the average coefficient of molecular packing equaled to 0.681 (for amorphous bulk polymers ${ }^{33,34}$ ).

\section{Author contributions}

The manuscript was written through contributions of all authors. All authors have approved the final version of the manuscript.

\section{Conflicts of interest}

There are no conflicts to declare.

\section{Acknowledgements}

Financial support from the Russian Science Foundation is gratefully acknowledged (project No. 15-13-30026).

\section{References}

1 L. Ruiz-Pérez, G. J. Royston, J. P. A. Fairclough and A. J. Ryan, Polymer, 2008, 49, 4475-4488.
2 C.-C. Lin, E. Parrish and R. J. Composto, Macromolecules, 2016, 49, 5755-5772.

3 M. Alcoutlabi and G. B. McKenna, J. Phys.: Condens. Matter, 2005, 17, R461-R524.

4 F. W. Starr, J. F. Douglas, D. Meng and S. K. Kumar, ACS Nano, 2016, 10, 10960-10965.

5 T. Davris, M. R. B. Mermet-Guyennet, D. Bonn and A. V. Lyulin, Macromolecules, 2016, 49, 7077-7087.

6 L. S. Schadler, S. K. Kumar, B. C. Benicewicz, S. L. Lewis and S. E. Harton, MRS Bull., 2007, 32, 335-340.

7 L. M. Hall, A. Jayaraman and K. S. Schweizer, Curr. Opin. Solid State Mater. Sci., 2010, 14, 38-48.

8 O. A. Serenko and A. M. Muzafarov, Polym. Sci., Ser. C, 2016, 58, 93-101.

9 J. Oberdisse, G. Carrot, J. Oberdisse, J. Jestin, F. Boué, E. Geissler, C. Gauthier and A. Zaoui, Soft Matter, 2006, 2, 29-36.

10 S. Kango, S. Kalia, A. Celli, J. Njuguna, Y. Habibi and R. Kumar, Prog. Polym. Sci., 2013, 38, 1232-1261.

11 Y. Tai, J. Qian, Y. Zhang and J. Huang, Chem. Eng. J., 2008, 141, 354-361.

12 Y. Tai, J. Qian, J. Miao, R. Xia, Y. Zhang and Z. Yang, Mater. Des., 2012, 34, 522-527.

13 O. A. Serenko, M. V. Mironova, N. A. Novozhilova, P. V. Strashnov, E. V. Getmanova, A. A. Askadskii, V. G. Shevchenko, V. G. Kulichikhin and A. M. Muzafarov, Mater. Chem. Phys., 2015, 156, 16-28.

14 A. Zhiltsov, O. Gritsenko, V. Kazakova, O. Gorbatsevitch, N. Bessonova, A. Askadskii, O. Serenko and A. Muzafarov, J. Appl. Polym. Sci., 2015, 132, 41894.

15 S.-K. Kim, N. A. Nguyen, J. J. Wie, H. S. Park, C. Schick, M. E. Seitz, K. I. Winey, N. Clarke and R. J. Composto, Nanoscale, 2015, 7, 8864-8872.

16 V. I. Roldughin, O. A. Serenko, E. V. Getmanova, N. A. Novozhilova, G. G. Nikifirova, M. I. Buzin, S. N. Chvalun, A. N. Ozerin and A. M. Muzafarov, Polym. Compos., 2016, 37, 1978-1990.

17 M. E. Mackay, A. Tuteja, P. M. Duxbury, C. J. Hawker, B. Van Horn, Z. Guan, G. Chen and R. S. Krishnan, Science, 2006, 311, 1740-1743.

18 A. R. de Luzuriaga, A. Etxeberria, J. Rodríguez and J. A. Pomposo, Polym. Adv. Technol., 2008, 19, 756-761.

19 J. B. Hooper and K. S. Schweizer, Macromolecules, 2005, 38, 8858-8869.

20 Y. Rao, Particuology, 2010, 8, 549-555.

21 A. Tuteja, P. M. Duxbury and M. E. Mackay, Phys. Rev. Lett., 2008, 100, 77801.

22 A. L. Frischknecht, E. S. McGarrity and M. E. Mackay, J. Chem. Phys., 2010, 132, 204901.

23 M. K. Crawford, R. J. Smalley, G. Cohen, B. Hogan, B. Wood, S. K. Kumar, Y. B. Melnichenko, L. He, W. Guise and B. Hammouda, Phys. Rev. Lett., 2013, 110, 196001.

24 T. Chen, H.-J. Qian, Y.-L. Zhu and Z.-Y. Lu, Macromolecules, 2015, 48, 2751-2760.

25 M. Seiler, Chem. Eng. Technol., 2002, 25, 237-253.

26 R. Hourani and A. Kakkar, Macromol. Rapid Commun., 2010, 31, 947-974. 
27 D. Astruc, E. Boisselier and C. Ornelas, Chem. Rev., 2010, 110, 1857-1959.

28 S. Ristić and J. Mijović, Polymer, 2008, 49, 4695-4702.

29 S. K. Emran, Y. Liu, G. R. Newkome and J. P. Harmon, J. Polym. Sci., Part B: Polym. Phys., 2001, 39, 1381-1393.

30 B. M. Tande, N. J. Wagner and Y. H. Kim, J. Polym. Sci., Part B: Polym. Phys., 2007, 45, 1970-1975.

31 N. A. Novozhilova, O. A. Serenko, V. I. Roldughin, A. A. Askadskii and A. M. Muzafarov, Silicon, 2015, 7, 155-164.

32 P. L. Carr, G. R. Davies, W. J. Feast, N. M. Stainton and I. M. Ward, Polymer, 1996, 37, 2395-2401.

33 A. A. Askadskii, Physical Properties of Polymers: Prediction and Control, Gordon and Breach Publishers, Amsterdam, 1996, vol. 2 .

34 A. A. Andrei and A. Askadskii, Computational materials science of polymers, Cambridge International Science Publishing, 2003.

35 A. Takano, Y. Ohta, K. Masuoka, K. Matsubara, T. Nakano, A. Hieno, M. Itakura, K. Takahashi, S. Kinugasa, D. Kawaguchi, Y. Takahashi and Y. Matsushita, Macromolecules, 2012, 45, 369-373.
36 O. A. Serenko, V. I. Roldugin, N. A. Novozhilova, M. A. Soldatov, G. G. Nikiforova, M. V. Mironova, S. O. Ilyin, V. G. Kulichikhin and A. M. Muzafarov, Polym. Sci., Ser. A, 2015, 57, 586-595.

37 J. Jancar, J. F. Douglas, F. W. Starr, S. K. Kumar, P. Cassagnau, A. J. Lesser, S. S. Sternstein and M. J. Buehler, Polymer, 2010, 51, 3321-3343.

38 M. Wong, R. Tsuji, S. Nutt and H.-J. Sue, Soft Matter, 2010, 6, 4482.

39 J. M. Kropka, K. W. Putz, V. Pryamitsyn, V. Ganesan and P. F. Green, Macromolecules, 2007, 40, 5424-5432.

40 L. M. Hall and K. S. Schweizer, J. Chem. Phys., 2008, 128, 234901.

41 F. Morgenroth, C. Kübel and K. Müllen, J. Mater. Chem., 1997, 7, 1207-1211.

42 U.-M. Wiesler, Charakterisierung und Funktionalisierung von Polyphenylen-Dendrimeren, $\mathrm{PhD}$ thesis, Johannes Gutenberg University, 2000. 